\title{
A FORMAÇÃO DO EXTENSIONISTA RURAL: DESAFIOS NO ENSINO TÉCNICO PROFISSIONAL EM PERNAMBUCO
}

\author{
Marco Antônio Gomes dos Santos ${ }^{1}$ \\ Irenilda de Souza Lima ${ }^{2}$ \\ Renata Sá Carneiro Leão ${ }^{3}$
}

\section{RESUMO}

Esse artigo faz parte de uma pesquisa que objetivou analisar a formação técnicoprofissionalizante de nível pós-médio em cursos técnicos ligados à Assistência Técnica e Extensão Rural (Ater) em Pernambuco. A partir de observações realizadas em campo, identificamos que em muitos casos, os extensionistas que realizam funções de Ater em Pernambuco, são oriundos de cursos técnicos oferecidos pelo Governo Federal. Através de entrevistas semiestruturas com estudantes e outros profissionais das instituições que fizeram parte desta pesquisa, encontramos no nível técnico-profissionalizante um descompasso semelhante ao verificado por Callou et al. (2008) - acerca da baixa integração entre o que é produzido na pós-graduação que não encontra respaldo no ensino de graduação -. O ensino de Assistência Técnica e Extensão Rural, fora do âmbito da pós-graduação em Pernambuco, continua marcado pela Teoria de Difusão de Inovações e por métodos cartesianos de ensino.

Palavras-chave: agricultura familiar, ATER, desafios, educação, ensino técnico profissional.

\section{EDUCATION OF RURAL EXTENSIONIST: CHALLENGES IN THE TECHNICAL PROFESSIONAL TRAINING IN PERNAMBUCO}

\begin{abstract}
This paper is part of a research that aimed to analyze the technical and vocational education post-secondary level in technical courses linked to the Technical Assistance and Rural Extension (TARE) in Pernambuco. From observations in the field, we found that in many cases, extension workers who perform TARE functions in Pernambuco come from technical courses offered by the Federal Government. Through Semi-structured interviews with students and other professionals of the

\footnotetext{
${ }^{1}$ Licenciado em História (UFRPE). Mestrado em Extensão Rural e Desenvolvimento Local (UFRPE). Assistente em Administração da Universidade Federal Rural de Pernambuco (UFRPE). E-mail: marcosantos743@gmail.com

${ }^{2}$ Graduada em Medicina Veterinária (UFRPE). Mestrado em Administração e Comunicação Rural (UFRPE). Doutorado em Ciências da Comunicação (USP). Professora Associada da Universidade Federal Rural de Pernambuco (UFRPE). E-mail: irenilima2@gmail.com

${ }^{3}$ Graduada em Jornalismo (UNICAP). Mestrado em Extensão Rural e Desenvolvimento Local (UFRPE). Assessora de Comunicação da Universidade Federal Rural de Pernambuco (UFRPE). E-mail: renatascleao@gmail.com
} 
institutions that were part of this research, we found the technical and professional level an disconnection similar to that seen by Callou et al. (2008) - about the low integration between what is produced in graduate school that is not supported in undergraduate teaching -. Education Technical Assistance and Rural Extension, outside the graduate level in Pernambuco, still marked by the Diffusion of Innovation Theory and Cartesian teaching methods.

Keywords: challenges, education, family farm, TARE, technical training.

\section{INTRODUÇÃO}

Este artigo é parte de uma pesquisa que buscou a analisar a formação do técnico agrícola de nível médio em Institutos Federais de Educação no Estado de Pernambuco. Trabalhamos aqui, além da revisão de literatura sobre Assistência Técnica e Extensão Rural (Ater), alguns resultados especificamente sobre o ensino de Extensão Rural enquanto componente curricular de cursos técnicos em agricultura e agropecuária. A justificativa para a pesquisa é a constatação da existência de um descompasso entre o que tem sido discutido e produzido em cursos de pós-graduação e em instâncias regionais e nacionais de debates sobre a ater, que não encontram reflexo no ensino de graduação e no ensino técnico, formadores de profissionais nessa área.

Acreditamos que os problemas que se manifestam nas instâncias políticoadministrativas e educacionais ligadas à agricultura no Brasil e, em especial, a agricultura familiar, se devem, em grande parte, à forma como se desenvolveu o processo de ocupação do país durante e após o período da colonização. A ocupação ocorreu, dentre outros aspectos, com o genocídio de povos de diversas tribos e troncos linguísticos dispersos pelo continente americano. O chamado Pacto Colonial visava a transformar as colônias em fornecedoras de gêneros comercializados pelas metrópoles europeias naquele continente, e foi aplicado em várias possessões americanas, tanto de Portugal quanto da Espanha (BUENO, 2006; FURTADO, 1987; PRADO JUNIOR, 1987).

Feita tal ressalva, podemos afirmar que, durante a formação do território brasileiro a partir da chegada do europeu, a atividade agropecuária foi sendo desenvolvida ora como atividade econômica principal, ora como atividade acessória, buscando tanto à exportação de gêneros primários, quanto à sobrevivência do colonizador e dos outros estratos sociais envolvidos no processo de miscigenação que viria dar origem ao povo brasileiro (PRADO JUNIOR, 1987; FURTADO, 1987).

A importância desse fenômeno é a compreensão de como o processo de organização social do Brasil coorganizou sua relação com a terra e com a produção agrícola. Além disto, procuramos mostrar de que forma o Estado vem se organizando, ao longo do tempo, para lidar com os desafios exigidos pelo campo, em uma realidade heterogênea e complexa de um país com dimensões continentais.

O principal produto agrícola do período colonial foi a cana-de-açúcar. Vale afirmar que outras culturas foram substituindo o açúcar, quando este entrou em declínio por causa da concorrência das Antilhas. Por outro lado, as hortas e pomares cultivados por escravos formaram boa parte da base alimentar desse período.

Os conhecimentos acumulados pelos povos que habitavam o território antes da chegada do invasor acabaram sendo úteis para a sobrevivência do europeu no Novo Mundo. Tavares de Lima (2010) aponta para várias culturas desenvolvidas por tribos e povos existentes, não apenas em relação ao cultivo, mas de inúmeros conhecimentos sobre plantas medicinais e animais, além de outros 
constituintes das cadeias alimentar e se ecossistemas ${ }^{4}$. Não podemos desconsiderar que a agricultura familiar, tal como conhecemos hoje, é, em boa parte, fruto dessa forma de uso do solo desenvolvida durante séculos por povos autóctones, e também pelos escravos, que viriam a ser a força motriz da indústria açucareira.

Localizando a questão agrária na contemporaneidade, consideramos que, apesar das significativas melhorias no apoio à agricultura de base familiar, ainda é predominante a preocupação com a exportação, mesmo considerando que o setor primário da economia há décadas perdeu sua hegemonia econômica. Se no início do século XX o Brasil era um país agrário exportador, em 2012, aproximadamente $5,2 \%$ do Produto Interno Bruto era proveniente da produção agrícola (CUNHA, 2013). Por outro lado, a maior parte da agricultura, cerca de $60 \%$, ainda tem como objetivo a exportação e a produção de commodities (IBGE, 2006).

O apoio governamental à agricultura familiar está associado às políticas públicas e, entre essas, figura o crescimento no apoio a atividades de assistência técnica e extensão rural. Considerando a Ater pública e, portanto, uma ação política ampla, longe de esgotar o tema, procuramos sintetizar pontos que consideramos cruciais para mostrar como historicamente tem havido preocupação das esferas governamentais com a criação de serviços de assistência técnica e de serviços educacionais e profissionalizantes ligados à produção agrícola.

No cenário político, existe uma longa batalha entre modelos de desenvolvimento diferentes, representada institucionalmente na presença de dois ministérios, que se encarregam de assuntos relacionados às políticas agrárias: o Ministério da Agricultura, Pecuária e Abastecimento (Mapa) - que foca suas ações na grande agricultura comercial/industrial, consumidora de insumos químicos e de maquinário pesado - e o Ministério do Desenvolvimento Agrário (MDA) - que tem como público-alvo os agricultores familiares, nos vários segmentos representados nesse termo, tais como pescadores artesanais, ribeirinhos, quilombolas e outros grupos definidos na Lei de Ater -. É desconsiderada, portanto, a existência de agricultores familiares que produzem nos moldes do agronegócio.

Callou (2006) defende a ideia da existência de múltiplos significados para a extensão rural. Segundo o autor, tal diversidade interpretativa serviu para o enriquecimento de debates acadêmicos, que também foram sendo incorporados com o decorrer da fundação dos serviços oficiais de Ater no Brasil. Entre os termos elencados estão: educação, ajuda técnica e financeira, desenvolvimento, difusão de inovações, educação dialógica, mobilização para participação sociopolítica e econômica, desenvolvimento local, entre outros.

Apesar da multiplicidade, para efeito de legislação, a definição de Ater válida oficialmente é a da Lei 12.188, de 11 de janeiro de 2010 (BRASIL, 2010), que instituiu a Política Nacional de Assistência Técnica e Extensão Rural (PNATER) e o Programa Nacional de Assistência Técnica na Agricultura Familiar e na Reforma Agrária (Pronater). Na Lei, a atividade é definida como um:

[...] serviço de educação não formal, de caráter continuado, no meio rural, que promove processos de gestão, produção, beneficiamento e comercialização das atividades e dos serviços agropecuários e não agropecuários, inclusive das atividades agroextrativistas, florestais e artesanais. (BRASIL, 2010, Art. 20, inciso I).

\footnotetext{
${ }^{4}$ De maneira geral, a matéria orgânica sempre segue um fluxo em um ecossistema. Esse fluxo começa no produtor, e segue suas etapas tróficas em direção ao decompositor que fará a reciclagem da matéria orgânica. É também conhecida como cadeia trófica.
} 
Ainda sobre os significados da extensão rural, Peixoto (2008) afirma que as definições variam de acordo com cada país ou localidade, mas que a extensão rural pode ser entendida como processo comunicativo, como instituição e como política. Enquanto processo comunicativo, seria o ato de estender, levar ou transmitir conhecimentos, não desconsiderando toda a crítica a essa concepção realizada a partir de Freire em 1969. Enquanto instituição, Ater refere-se às organizações estatais e prestadoras de serviços. Já na concepção de política pública, seriam as ações traçadas pelos governos, em todas as esferas, através de dispositivos legais ou programáticos, executadas por instituições públicas e/ou privadas para aquele fim. O autor ainda afirma que a extensão rural, em seu caráter educativo, dificilmente está dissociada da prestação de serviços de assistência técnica.

Há uma relação entre a política e o modelo de extensão rural resultante adotado por um país e pelas estruturas institucionais que se consolidam. No Brasil, privilegiou-se o modelo público e gratuito, hoje direcionado prioritariamente para os agricultores familiares pelas instituições estaduais de Ater (PEIXOTO, 2008). Cabe ressaltar que várias organizações não governamentais e da sociedade civil também se encarregam da tarefa de prestação desses serviços.

\section{REFERENCIAL TEÓRICO}

\subsection{Serviço oficial de extensão rural no Brasil}

A chegada de serviços estatais de assistência ao pequeno agricultor não foi efetiva na maioria dos casos. Durante décadas, privilegiou-se o desenvolvimento do agronegócio em detrimento das peculiaridades da agricultura familiar. Essa discrepância tem origem na institucionalização dos serviços de Ater, a partir da criação da Associação de Crédito e Assistência Rural (ACAR), em Minas Gerais, em 1948, sob influência da família Rockfeller, que seguiu os moldes das Land Grant Colleges norte-americanas, voltadas às atividades para disseminar novas práticas e conhecimentos agrícolas na perspectiva de educação informal (CALLOU, 2006).

O Estado de Minas Gerais foi escolhido por causa da experiência existente em Viçosa, além da abundância de recursos naturais e da burguesia com forte poder de negociação, disposta a colocar o Estado no centro do país. Viçosa possuía uma Escola Superior de Agricultura, embrião da Universidade Federal de Viçosa, e, desde 1929, realizava feiras anuais de ruralistas, que tinham significativo impacto local e regional. Essas feiras, mais tarde, passaram a ser realizadas em quase todo o país, através de convênios do Ministério da Agricultura com as secretarias de agricultura dos estados (CALLOU, 2006; OLINGER, 2006).

Posteriormente, em 1956, no governo de Juscelino Kubitschek, houve a criação da Associação Brasileira de Crédito e Assistência Rural (ABCAR), que trazia não apenas o sentido da educação, mas também visava a uma agricultura mais moderna, de caráter químico e mecânico, com recursos creditícios orientados a regiões consideradas mais promissoras. Porém, 0 fato acarretou a exclusão paulatina do pequeno agricultor da ótica dessas ações (CALLOU, 2006).

Na década de 1970, durante a Ditadura Militar, o governo de Ernesto Geisel tornou o serviço de Ater federal, com a implantação do Sistema Brasileiro de Assistência Técnica e Extensão Rural (SIBRATER), que fora coordenado pela Empresa Brasileira de Assistência Técnica e Extensão Rural (EMBRATER) e executado por empresas de Ater nos Estados, conhecidas genericamente pelo nome de Emater. A Embrater era responsável pela destinação de vultosos recursos 
administrados pelos Estados, a partir dos quadros técnicos de empresas especializadas (BRASIL, 2004).

Para Lima e Roux (2008), enquanto prevalecia a política desenvolvimentista do pós-guerra, o modelo de Ater aplicado no Brasil tinha como base a Teoria da Difusão de Inovações, de Everett Rogers, publicada inicialmente em $1962^{5}$, e os pacotes tecnológicos da chamada Revolução Verde. As estratégias de comunicação eram do tipo persuasivo, e não se consideravam os saberes locais e práticas agrícolas tradicionais já existentes. Essas estratégias não atingiram o pequeno e médio agricultor, porque não tinham essa finalidade, mas foram eficientes para os grandes produtores, que seguiram à risca, alimentando bons êxitos nas exportações.

Silva et al. (1983, p. 22), analisando os impactos da tecnologia e do sistema de crédito junto ao campesinato, há aproximadamente trinta anos, afirmavam que:

\begin{abstract}
Quanto à organização institucional para a geração e difusão de tecnologia, ressalta-se o papel do setor público, através dos seus dois organismos básicos (a EMBRAPA e a EMBRATER), na implementação de uma política tecnológica que não favorece os pequenos produtores. Ao contrário, a nova organização institucional baseada fundamentalmente em linhas de pesquisa por produto e na centralização dos recursos disponíveis tende a reforçar as penalizações que já são impostas pelo sistema econômico ao setor de pequenos produtores.
\end{abstract}

A Ater executada então, era profundamente influenciada pela Revolução Verde, que, por sua vez, causou e ainda vem causando efeitos nocivos, não só do ponto de vista da agricultura, mas também da ótica sociopolítica, pois permanece como modelo de produção hegemônico em escala global.

[...] a Revolução Verde contribuiu para aumentar a produção e produtividade de alguns cultivos e criações em algumas regiões do planeta, também é certo que onde ela foi levada ao seu extremo, foi responsável por danos ambientais e níveis de exclusão social de desproporcional grandeza. Em geral, o modelo "científico" da Revolução Verde continua sendo causador de destruição da biodiversidade (ainda que tentemos ter leis de proteção), continua estreitando a base genética da qual depende nossa alimentação, continua enfatizando os monocultivos e a produção de commodities, em detrimento da diversificação de cultivos e da produção de alimentos básicos adequados aos diferentes hábitos alimentares e dietas das distintas populações(CAPORAL, 2008, p. 5).

Na década de 1990, através da Lei 8.029, de 12 de abril de 1990 (BRASIL, 1990), veio o desmantelamento do serviço de Ater, durante o Governo Collor de Melo, que foi um duro golpe para a agricultura familiar (LIMA e ROUX, 2008). Considerava-se que não havia necessidade de assistência ao grande produtor rural, que caminhava por conta própria, aliada à ideia do fim da agricultura não industrial.

Sobre o montante de recursos que deixariam de ser destinados para as unidades da EMATER, Hoffmann (1990) deixa claro que os setores que receberiam

\footnotetext{
${ }^{5}$ Para com Rogers $(2003$, p. 5) "Diffusion is the process in which an innovation is communicated through certain channels over time among the members of a social system". Em tradução livre, "Difusão é o processo pelo qual uma inovação é comunicada por certos canais durante um certo tempo, dentre os membros de um sistema social".
} 
o maior impacto localizavam-se nos estados que mais necessitavam da assistência federal.

No passado recente, a EMBRATER contribuía com cerca de $40 \%$ dos recursos absorvidos pela EMATER-RS. Em 1989, esse montante ficou em apenas $12 \%$, sendo que, para 1990 , estava previsto um aporte de cerca de $20 \%$. Já no Nordeste, esse montante atinge historicamente, em alguns estados, a $80 \%$ dos recursos das EMATERS (HOFFMANN, 1990, p. 59).

As críticas a esse modelo não tardariam a aparecer. Ainda em 1969, o educador brasileiro Paulo Freire publicou, no Chile, a obra Extensão ou Comunicação?, na qual tece pesadas críticas ao fato de os extensionistas tratarem os agricultores como sujeitos passivos, ignorando seus conhecimentos frutos de uma longa correlação com o meio ambiente. Para os extensionistas, o modelo de comunicação deveria ser por persuasão, levando os agricultores a adotar os pacotes tecnológicos que lhes eram ofertados pelo Estado (FREIRE, 1983).

A extensão rural criticada por Freire (1983) é aquela que suprime o caráter educativo das atividades em função de mera propagação de ideias para mentes desprovidas de conhecimento, que receberiam, de forma mecânica, os ensinamentos fornecidos pelos extensionistas. O autor acredita que os trabalhos relacionados à educação popular devem se estabelecer a partir da comunicação dialógica, aprofundando a tomada de consciência da realidade.

Por outro lado, através da análise da historiografia clássica, vemos que o Brasil possui uma estrutura histórica que pouco possibilitou ao agricultor familiar permanecer no campo. Desde a chegada dos colonizadores, para cumprir sua função no pacto colonial, a agricultura brasileira foi voltada para a exportação de gêneros diversos para a Metrópole europeia, que, por sua vez, comercializava no porto de Lisboa as riquezas expropriadas da Colônia. A exploração do açúcar, devido à baixa qualidade técnica, só era viável em grandes extensões de terra, propiciando a formação de latifúndios, que eram trabalhados, em quase sua totalidade, pela mão de obra escrava (FURTADO, 1987; PRADO JUNIOR, 1987).

A pecuária, realizada até então de maneira extensiva, por ausência de fronteiras, também contribuiu para a formação de grandes propriedades de terra. Vale citar que os trabalhadores poderiam iniciar suas criações, tendo em vista que o pagamento pelo trabalho com o gado era feito com parte da produção, pois quase não havia circulação de moedas. Mesmo com o cultivo de outros gêneros, quando o açúcar entrou em declínio, até a chegada do café, em meados do século XIX, os poderes instituídos sempre criaram mecanismos para impedir a posse da terra ao trabalhador (PRADO JUNIOR, 1987; FURTADO, 1987). Essa estrutura não mudou, mesmo no século XX, sendo debeladas violentamente todas as revoltas que ocorreram tendo como pano de fundo a questão agrária brasileira.

A esperança de mudanças viria a renascer com a abertura proposta no Governo Lula (2002-2010), quando o MDA passou a ser responsável pelas atividades de Ater, através do Decreto 4.739, de 13 de junho de 2003 (BRASIL, 2003). A Secretaria da Agricultura Familiar (SAF/MDA) recebeu a incumbência de coordenar a construção de uma nova Política Nacional de Ater que levasse em conta o imperativo socioambiental, tendo como foco os agricultores familiares, assentados, quilombolas, pescadores artesanais, dentre outros (BRASIL, 2004).

A PNATER de 2004 reconhece os resultados negativos da Revolução Verde e de outros problemas encontrados em estudos sobre modelos convencionais de Ater, embasados pela teoria de difusão de inovações. Entre esses problemas, 
estão, por exemplo, a dependência do agricultor de capital para aquisição de tecnologias agrícolas, que inviabilizou a pequena produção pela não consecução de crédito. Andrade e Tauk Santos (2015, p. 31), com o advento da política, afirmam que "era preciso superar o fracasso que representou o modelo baseado na Difusão de Inovações apregoada pela Revolução Verde, que gerou exclusão social sem precedentes no campo e degradou o meio ambiente em todos os cantos do país".

Guimarães (2011), ao analisar o documentário O veneno está na mesa, de Silvio Tendler, enfatiza que, ao aderir aos kits agronômicos, o agricultor torna-se ligado a um sistema do qual não consegue escapar, devido ao condicionamento da produção viciada em insumos, cujo retratamento torna-se impossível às suas expensas. Esse modelo age de forma a torná-lo preso ao mercado, através de definições externas que o excluem do direito de produzir para consumo familiar e para pequenos circuitos de comercialização, trocas e consumo.

Voltando à construção da PNATER, observamos uma ampla participação de diversos setores da sociedade. Podemos elencar diversas esferas do governo federal, unidades federativas e suas instituições, assim como segmentos da sociedade civil, lideranças de organizações representativas dos agricultores familiares e movimentos sociais comprometidos com o campo (BRASIL, 2004).

Em seus objetivos, a PNATER trazia a agroecologia como eixo orientador de ações de Ater, buscando estimular atividades agrícolas, não agrícolas e pesqueiras, visando ao fortalecimento da agricultura familiar (BRASIL, 2004). Porém, quando foi promulgada a Lei 12.188/2010, conhecida como Lei de Ater, a agroecologia foi retirada do texto final.

Caporal (2011, p. 25) afirma que a agroecologia foi substituída por um princípio de eficácia duvidosa- que fala na "adoção dos princípios da agricultura de base ecológica como enfoque preferencial (sic) para o desenvolvimento de sistemas de produção sustentáveis" - e essa mudança abre caminho para um retorno ao velho modelo difusionista e produtivista, pois, ao longo de 2010, das 148 chamadas de projetos de ater, apenas 28 tinham a transição agroecológica entre suas linhas de ação. O modelo que comprovadamente não resolveu os problemas da produção agrícola do Brasil está vivo e ainda com grande força nas práticas de ensino e nas empresas estaduais de Ater.

As críticas não são relacionadas apenas ao caráter socialmente excludente do modelo hegemônico de produção agrícola, mas aos danos ambientais que o mesmo tem provocado. Entre os principais impactos estão os altos níveis de $\mathrm{CO}_{2}$ emitidos; envenenamento de lençóis freáticos, do solo, das plantas e alimentos; desertificação; desmatamento; desequilíbrio climático, entre outros (WEISSHEIMER, 2006; BUNDE; MENDONÇA, 2009).

Torna-se impossível levantar aqui todas as críticas à forma como a Ater foi desenvolvida ao longo de mais de 60 anos, todavia fica clara a importância da discussão sobre uma extensão rural pensada fora dos limites de um modelo econômico focado no crescimento da produtividade a qualquer custo, que deixa de lado questões que incidem e influem diretamente sobre o campesinato.

Cabe-nos ainda lembrar do fenômeno da globalização ${ }^{6}$ e da consequente perda de autonomia dos Estados nacionais em favor das agências e organismos multilaterais como Banco Mundial, Banco Interamericano de Desenvolvimento, Organização Mundial do Comércio, entre outros.

Giddens (1990 apud SANTOS, 2005, p. 26) define a globalização como "a intensificação das relações sociais mundiais que unem localidades distantes de tal

\footnotetext{
${ }^{6}$ Para aprofundamento sobre o tema globalização, consultar SANTOS, B. S. A globalização e as ciências sociais. São Paulo: Cortez, 2005.
} 
modo que os acontecimentos locais são condicionados por eventos que acontecem a muitas milhas e distância e vice-versa". Essa intensificação dramática trouxe consigo a radicalização de um modelo de desenvolvimento calcado nas leis de mercado, que atinge todos os setores da economia e da vida social das populações.

Decerto, boa parte das transformações ocorridas no rural, a partir de meados do século $X X$, se dá pelos esforços elencados para o desenvolvimento do capitalismo; entre eles, a globalização dos mercados. A própria Ater institucionalizada no Brasil deriva de um esforço do pós-guerra norte-americano de tomar para si possíveis mercados consumidores emergentes, impondo a Doutrina Truman ${ }^{7}$ aos países em desenvolvimento, sob o risco de deixá-los vulneráveis ao que chamaram de ameaça comunista. Como relembra Callou (2006), não é à toa que a extensão rural brasileira nasce sob auspícios da família Rockfeller, com as ações dos extensionistas transfiguradas em ajuda técnica e financeira, que era a perspectiva adotada pela Farm Security Adminstration (FMA/USA) para ajudar os agricultores norte-americanos, sob a égide do governo devido à Grande Depressão de 1929.

\subsection{Estado da arte do ensino de extensão rural no Brasil}

Após localizarmos extensão rural no âmbito brasileiro, evidenciamos os desafios na formação de quadros profissionais para a execução de uma Ater como instrumento de apoio ao desenvolvimento da agricultura familiar, considerando as exigências contemporâneas de uma ação educativa com metodologias participativas, incentivo aos grupos associativos, diálogo de saberes pela comunicação dialógica e tendo a agroecologia como modelo inspirador de práticas sustentáveis e complexas.

Pensar nesse profissional nos remete diretamente à sua formação. O tema é complexo e vem passando por reformulações de vidas principalmente aos desafios relacionados ao atendimento aos agricultores de vários estratos sociais. Historicamente essas ações ficaram por conta do Estado e de suas unidades federativas, cabendo relatar que, apesar da tendência à municipalização de políticas públicas, legitimada pela Constituição Brasileira de 1988, são poucos os municípios que dispõem de estrutura para atender a demanda de serviços de Ater.

Para Callou et al. (2008), a obra Extensão ou Comunicação?, de Freire, permeia uma ruptura com o ensino universitário tradicional, pautado no difusionismo modernizador da agricultura. Esse assunto se faz atual e presente dentro de um estado de crises pelas quais passam a academia, o mundo do trabalho e os referenciais de análise típicos da ciência cartesiana. Somam-se ainda problemas não resolvidos e exacerbados no início do século XXI, como a exclusão social, a falta de acesso à terra, a insustentabilidade do modelo de exploração de recursos naturais, problemas para os quais se precisa de novos referenciais de análise e respostas urgentes.

Nesse estado de múltiplas crises, encontramos a disciplina Extensão Rural às voltas com discursos sobre sua exclusão dos programas de ensino. Alemany e Sevilla Guzmán (2006, p. 7), ao analisarem o processo de desenvolvimento da Ater norte-americana exportada para a América Latina, afirmam que:

\footnotetext{
${ }^{7}$ Doutrina Truman representou um conjunto de práticas dos Estados Unidos da América para conter o avanço do socialismo junto aos elos frágeis do sistema capitalista. A doutrina se mistura intimamente com a Guerra Fria ou ameaça de guerra que marcou a ordem bipolar após a $2^{a}$ Guerra Mundial. Buscava-se ajudar países em dificuldades financeiras, com oferta de crédito para aceleração do capitalismo, inclusive com financiamento de ditaduras de direita, que foram marcantes na América Latina após a segunda metade do século XX.
} 
De esta manera, la extensión convencional desarrolla una trayectoria en la cuál, primero ayuda a generar las condiciones culturales y económicas para iniciar los procesos de modernización, posteriormente constituye un arma poderosa para la transferencia de los paquetes tecnológicos de la Revolución Verde que consolidan el uso industrial de los recursos naturales $y$, finalmente, cuando la tarea de transformación de la agricultura en una rama de la industria está cumplida, se plantea su desaparición como disciplina científica.

Acerca do ensino e da pesquisa em extensão rural, Callou et al. (2008) indicam que há baixa integração entre a pós-graduação e os níveis de graduação e técnico profissionalizante. Enfatizamos que este último tem sido formador de uma ampla gama de extensionistas, que, muitas vezes, são a primeira linha de contato do agricultor com as políticas públicas (SANTOS, 2014).

Pensamos que essas instâncias formativas devem ser contempladas nas discussões permanentes sobre a Ater e sua necessidade de revisão e incorporação dos múltiplos pontos da realidade rural brasileira. Entre essas discussões, apresenta-se a carência de profissionais preparados para exercerem esse ofício de acordo com as demandas atuais.

Como novos referenciais de análise, Callou et al. (2008, p. 87) apontam para:

\begin{abstract}
a reorganização do trabalho e da produção dentro de uma ótica do associativismo/cooperativismo e da economia solidária; as desigualdades sociais associadas a gênero, etnias e geração; as concepções de desenvolvimento, que promovem o empoderamento dos contextos sociais excluídos, tal como descritas no Desenvolvimento Local; a expansão das novas tecnologias de comunicação e informação; a perspectiva comunicacional, que considera as populações do meio rural como sujeitos que reagem às políticas governamentais e nãogovernamentais como produtores de sentido; os movimentos sociais pela terra; a agricultura familiar e suas relações com a segurança alimentar; a representatividade das atividades nãoagrícolas e, mais recentemente, a agroecologia.
\end{abstract}

O trabalho a que nos referimos acima é a tentativa de realizar um mapa da extensão rural no Brasil. Foi apresentado no Seminário Comemorativo dos 60 Anos da Extensão Rural no Brasil, em Itamaracá-PE, 2008, sob o título Estado da Arte do Ensino de Extensão Rural no Brasil e posteriormente publicado na Revista de Extensão Rural de Santa Maria. Por sua vez, traz vários resultados interessantes sobre o andamento do ensino e da pesquisa de extensão rural no país.

O mapa demonstra que pesquisas envolvendo agricultura familiar, desenvolvimento local, agroecologia e movimentos sociais estavam presentes em mais de $60 \%$ dos projetos dos respondentes, enquanto pesquisas relacionadas à geração, gênero e etnias não chegavam a 10\%. Projetos ligados à extensão pesqueira simplesmente não foram citados entre os respondentes nas regiões Sul, Sudeste e Centro-Oeste (CALLOU et al., 2008).

No que se refere às temáticas de atividades não agrícolas, que, segundo Campanhola e Silva (2004 apud CALLOU et al., 2008), representam mais de 50\% das atividades produtivas da população do campo, houve pouco mais de $3 \%$ de 
menção entre os pesquisadores da Região Sudeste, não sendo sequer mencionado no Norte. O tema da reforma agrária apareceu discretamente em pouco mais de $5 \%$ dos projetos de pesquisa informados. Esses assuntos também apresentam a mesma tendência de pouca expressão nos projetos de extensão.

A componente curricular Extensão Rural apareceu como obrigatória nas matrizes dos cursos de graduação em $90 \%$ das respostas, com carga horária variando entre vinte e noventa horas-aula e predominância em sessenta horas-aula. Os números nos parecem insuficientes para tratar da complexidade do trabalho de extensionista. Ainda foi constatado baixo nível de integração entre as atividades de pesquisa/pós-graduação com os cursos de graduação (CALLOU et al., 2008).

De forma geral, o que ocorre nos projetos de pesquisa se assenta nas disciplinas. Características iniciais das críticas, principalmente com base em Freire (1983) estão presentes, mas temas como pesca e extensão pesqueira, geração, gênero, etnia, novas ruralidades, entre outros, ainda são pouco debatidos ou explorados. Contudo, nos objetivos e ementas das disciplinas, aparecem temas importantes como o diálogo de saberes e a busca pela sustentabilidade oposta ao que é preconizado nos modelos da Revolução Verde (CALLOU et al., 2008).

Quanto à PNATER, foi constatado que quase $80 \%$ das ementas de disciplinas de extensão rural no Brasil abordavam temas referentes à política:

Assim sendo, dentre os temas elencados como relacionados à política de Ater, foram citados: "desenvolvimento rural sustentável"; "agricultura familiar"; "inclusão social"; "uso sustentável dos recursos naturais"; "associativismo, cooperativismo"; e "metodologias participativas", entre outros (CALLOU et al., 2008, p. 103).

Esses temas também aparecem de forma transversal, com maior ou menor intensidade em outras disciplinas que estão ligadas a contextos rurais, como sociologia, educação agrícola, marketing e administração rural, cooperativismo/associativismo, etc. Percebe-se, dessa forma, que a extensão rural ainda enfrenta problemas ligados à herança ou forma histórica de execução, além da forte presença do tecnicismo em suas bases e da falta de concatenação com problemas sociais que exigem sua atenção.

Recentemente tem-se procurado realizar reflexões permanentes sobre extensão rural na sua condição componente curricular. Os seminários nacionais ocorridos em Itamaracá (2008) e Santa Maria (2010) procuraram apontar diretrizes para o ensino de Ater. Em março de 2012, a I Jornada de Ensino em Extensão Rural, realizada na Universidade Federal Rural de Pernambuco (UFRPE), se propôs a discutir a crise pela qual essa disciplina vem passando no âmbito das ciências agrárias no Brasil, com o intuito de enviar diretrizes para o enfrentamento da questão junto à I Conferência Estadual de Ater. Essa, por sua vez, compunha uma das bases estaduais da Conferência Nacional sobre Assistência Técnica e Extensão Rural na Agricultura Familiar e na Reforma Agrária (CNATER), realizada entre 23 e 26 de abril de 2012, que teve como objetivo a proposição de diretrizes para 0 Pronater, instrumento que orienta as ações da PNATER.

Da I Jornada de Ensino em Extensão Rural, resultou a Moção do Fórum Nacional de Ensino em Extensão Rural, que propunha, para a conferência nacional, entre outras ações, aqui de maneira resumida: mudanças nos currículos e projetos pedagógicos; articulação dos currículos de universidades e institutos de educação tecnológica responsáveis pela formação de profissionais de Ater; criação de processos de formação continuada para agentes de Ater; utilização de metodologias 
participativas e pedagogias construtivistas, inclusive camponês-camponês, junto aos agricultores e nos intercâmbios entre extensionistas; uso da pedagogia da alternância em cursos de ciências agrárias e ciências sociais aplicadas que ofereçam a componente curricular Extensão Rural (FORUM NACIONAL DE ENSINO EM EXTENSÃO RURAL, 2012).

O documento ainda traz a necessidade da reformulação das Diretrizes Curriculares Nacionais dos Cursos das Ciências Agrárias e Ciências Sociais Aplicadas; da formação continuada para os gestores ou executores de ações de Ater e da promoção de metodologias de conhecimento agroecológico. As reformulações devem levar em conta os avanços construídos nos dois fóruns sobre ensino de extensão rural, ou seja, o diálogo de saberes, a inter, trans e multidisciplinaridade e o espaço permanente para discussão. Também se afirma a necessidade de as universidades trabalharem junto ao Fórum para a criação dos cursos de formação continuada, criação de planos de cargos e carreiras nas instituições estaduais e um plano plurianual para garantir o lançamento de editais específicos para sistematização de experiências de ensino dentro de extensão rural e de extensão pesqueira (FORUM NACIONAL DE ENSINO EM EXTENSÃO RURAL, 2012).

Observamos, com a leitura do documento, a importância da integração do ensino técnico profissionalizante, articulando suas particularidades com os currículos das universidades e institutos federais responsáveis pela formação de profissionais de Ater. A formação do extensionista deve levar em conta o conhecimento dos processos e da realidade do meio, visando à necessidade de uma ação que promova mudanças e melhoria da qualidade de vida, principalmente dos agricultores/as assistidos/as e a repercussão desta ação.

\section{PROCEDIMENTOS METOLÓGICOS}

Considerando a complexidade de temas que os extensionistas têm contato no seu campo profissional e educacional, bem como os resultados da pesquisa de Callou et al. (2008), que revelam um descompasso entre os temas discutidos na pós-graduação e sua integração com a graduação, procuramos observar a relação desses temas com a formação técnica profissionalizante de nível médio em cursos ligados às ciências agrárias.

Em observação ao proposto por autores como Caldart (2009) e Lima (2002) e pela análise das possibilidades profissionais para extensionistas relatadas na pesquisa que deu origem a esse artigo, afirmamos que a ausência de conhecimentos acerca da Ater é prejudicial ao técnico formado, pois Ihe tira a possibilidade de exercer profissionalmente funções na área de pesquisa ou no trabalho de campo. Também, corre-se o risco de formar um profissional com pouca capacidade crítica e sem condições de intervir na realidade com a qual terá que lidar no seu campo de trabalho.

Nossa escolha de análise pelo nível técnico se deu por constatarmos, durante atividades didáticas de campo nas aulas de Extensão Rural - como disciplina de pós-graduação do Programa de Pós-Graduação em Extensão Rural e Desenvolvimento Local da UFRPE -, que muitos dos profissionais atuantes em funções de Ater ocupavam cargos de nível técnico pós-médio em órgãos estaduais, a exemplo do Instituto Pernambucano de Agricultura (IPA) e ONGs como o Centro Sabiá e a Diaconia, entre outras.

Vale frisar que, segundo nossas atividades em campo, técnicos de nível médio figuram, em muitos casos, como a primeira linha de contato entre os homens e mulheres do campo e as políticas públicas voltadas para o meio rural. Esses 
profissionais são formados, em grande parte, nos cursos oferecidos pelo Governo Federal, através de seus institutos federais de educação, ciência e tecnologia (IFs) e também em colégios agrícolas vinculados a instituições federais de nível superior, como é o caso do Colégio Agrícola Dom Agostinho Ikas (Codai), vinculado à Universidade Federal Rural de Pernambuco.

Esses órgãos ofertam vários cursos ligados às especificidades agrárias, tais como técnico em agricultura, técnico em agropecuária, técnico em agricultura familiar, técnico em agroindústria e até mesmo especialização pós-técnica, no caso do curso de Especialização em Cana-de-Açúcar oferecido pelo Codai/UFRPE.

Metodologicamente, optamos por realizar a pesquisa em pelo menos dois cursos vinculados a instituições diferentes, tendo em vista podermos generalizar resultados, o que não conseguiríamos com um estudo de caso. Além do Curso Técnico em Agropecuária do Codai, realizamos nossa pesquisa no curso Técnico em Agricultura da antiga Escola Agrotécnica de Vitória de Santo Antão, que, em 2008, por conta da legislação federal, foi vinculada ao Instituto Federal de Educação, Ciência e Tecnologia do Estado de Pernambuco (IFPE).

Considerando a extensa carga teórica que permeia a extensão rural, procuramos realizar uma minuciosa análise das ementas e conteúdos programáticos de todas as disciplinas que compõem os cursos, tendo em vista a possibilidade de encontrarmos temas relacionados à extensão em outras componentes curriculares, como alertam Callou et al. (2008).

Optamos por realizar uma pesquisa de viés qualitativo, por entendermos que essa seria a melhor forma de compreensão do nosso objeto de pesquisa. Minayo (1996) pondera que o método qualitativo destaca o universo de significados, motivos, aspirações, crenças, valores e atitudes, o que corresponde ao universo mais profundo das relações, dos processos e dos fenômenos que não podem ser reduzidos à operacionalização de variáveis.

A partir dessa opção, utilizamo-nos de pesquisa documental (GIL, 2002), bem como de entrevistas semiestruturadas para coleta de dados, que, de acordo com Trivinõs (1987, p. 152), "favorece não só a descrição dos fenômenos sociais, mas também sua explicação e a compreensão de sua totalidade". Optamos pela realização de entrevistas com os discentes dos últimos períodos dos cursos, pois já teriam travado contato com a maior parte da carga teórica de suas matrizes curriculares, além coordenadores e outros que se dispusessem a participar através de termo de consentimento livre e esclarecido. Vale ressaltar ainda que os dois cursos analisados eram da modalidade subsequente, logo, só permitiam ingresso do discente após a conclusão do ensino médio.

\section{RESULTADOS E DISCUSSÃO - DESAFIOS NA FORMAÇÃO EXTENSIONISTA}

Entre nossos objetivos com a apresentação desse artigo, está o de mostrar o que consideramos desafios na formação de extensionistas. Por uma série de considerações explícitas anteriormente, localizamos nossa análise na formação de profissionais de nível técnico em duas instituições federais, que, apesar de denominações diferentes em relação aos nomes dos cursos, estão enquadradas no mesmo eixo tecnológico de Recursos Naturais, de acordo com o Catálogo Nacional de Cursos Técnicos (MEC, 2012).

Vale ressaltar que a análise realizada em uma dissertação de mestrado nos rendeu vários resultados, que, metodologicamente, não cabem no âmbito deste trabalho. Pretendemos demonstrar, adiante, os resultados que estão diretamente ligados à extensão rural como componente curricular, e suas relações enquanto 
campo de conhecimento integrante dos projetos formativos dos técnicos em ciências agrárias.

O primeiro dado que nos chamou a atenção foi que, em ambos os cursos, encontramos turmas com lotação bem abaixo de suas entradas iniciais. No Codai, havia apenas onze discentes, considerando os turnos vespertino e matutino, onde deveria haver sessenta estudantes. Realizamos entrevistas com sete discentes, ou seja, mais de 50\% do universo disponível. No IFPE, Campus Vitória de Santo Antão, a situação era ainda mais grave. Havia apenas três alunos em uma entrada de quarenta. Como nesse caso, não havia turma ativa no último semestre, realizamos nossa entrevista com alunos do segundo semestre. Várias foram as causas elencadas para o abandono. Uma delas, em especial, relatada pela coordenadora de Ensino do IFPE, dizia respeito à ideia de que, para melhorar de vida, os estudantes alegavam que era necessário "sair do campo", "sair do atraso".

Vale citar que autores como Abramovay (2007), Brumer e Spavanello (2008) trabalham a questão da permanência dos jovens em contextos rurais e relatam que são várias as causas que levaram ao esvaziamento do campo nas últimas décadas. Entre elas, a questão da renda, a penosidade do trabalho agrícola e mesmo a desvalorização social da ocupação. Não cabe aqui uma análise detalhada dessas causas, mas fazemos menção a elas, pois estão na agenda de temas discutidos no contexto da Ater, enquanto política pública pela qual se busca a melhoria da qualidade de vida no campo.

Em relação aos casos específicos de cada instituição de ensino, no Colégio Agrícola Dom Agostinho Ikas, não encontramos disciplina específica de extensão rural na matriz curricular do curso Técnico em Agropecuária. Procuramos então nos debruçar sobre outras ementas, porém a ausência de temas sobre a Ater continuou. Mesmo disciplinas como Agricultura Geral, Culturas Regionais I e II apresentaram um caráter puramente técnico, além de não haver bibliografia disponível para embasá-las nos documentos analisados. A ausência se estende à PNATER e à Lei de Ater, que também não são referidas nas ementas de forma geral.

No documento que regia o funcionamento do curso Técnico em Agropecuária, durante o período de coleta de dados - outubro a novembro/2013 válido a partir do ano de 2010, um dos objetivos era:

\begin{abstract}
Instrumentalizar os estudantes para: Fiscalizar produtos de origem vegetal, animal e agroindustrial. Realizar medição, demarcação e levantamentos topográficos rurais. Atuar em programas de assistência técnica, extensão rural $e$ pesquisa (CODAl, 2009, p.10, grifo nosso).
\end{abstract}

Porém, verificamos que essa referência não se coadunava com a matriz curricular. Podemos afirmar que ela aparece isolada em todo o documento, não havendo nem mesmo bibliografia citada que trate de temas relacionados à Ater.

Para os discentes entrevistados, o curso estava aquém se suas expectativas por diversos motivos. Dentre os quais, eles consideravam a matriz curricular defasada frente às necessidades do mercado de trabalho, além de criticarem a ausência de prática, seja por meio de estágios, seja por meio de aulas de campo.

Perdicaris e Souza (2005, p. 31) concebem que a educação profissional deve ser formulada e efetivada em uma relação de unidade entre teoria e prática. Para as autoras, a prática pedagógica baseada na unidade tem um caráter criador, e a prática social é quem orienta sua ação. "Procura compreender a realidade sobre a qual vai atuar e não aplicar sobre ela uma lei ou modelo previamente elaborado". 
Consideramos que essa visão dicotômica entre teoria e prática trabalha contra a efetivação do processo formativo. Essa ausência é sentida pelos estudantes no que diz respeito também aos estágios. A Lei 11.788 , de 28 de setembro de 2008 (BRASIL, 2008), que regula mecanismos de estágios de estudantes, concebe o estágio como parte do projeto pedagógico do curso, integrando o itinerário formativo do estudante.

Em relação às experiências práticas, foram poucos relatos, que, em sua maioria, se davam por conta de experiências anteriores de jovens que eram filhos de agricultores. A única experiência, durante o curso, com agricultura familiar, havia sido uma visita a um assentamento onde o(a)s assentado(a)s ocupavam-se das etapas de produção em uma casa de farinha. Os discentes ainda relataram não terem conhecimento sobre a Lei de Ater e sobre o trabalho dos extensionistas rurais.

Em entrevista com o diretor da instituição, o mesmo reconheceu a importância da formação para extensão rural e sua relevância no apoio à agricultura familiar. Por outro lado, alegou que não havia, no Codai, nenhuma "política implementada" para a extensão rural, pois culturalmente muitos docentes acreditavam que extensão significava apenas convencer os agricultores a adotarem os conhecimentos científicos como verdades absolutas.

Contudo, o diretor relatou experiências em projetos de pesquisa que, apesar de não serem ações regulares, por vezes colocavam discentes em contato com a realidade da extensão rural. Porém essas ações eram dependentes de participações isoladas de docentes em alguma atividade dessa natureza.

No IFPE, Campus Vitória de Santo Antão, de maneira geral, a situação encontrada diferiu parcialmente da realidade do Codai. Havia, na matriz curricular do curso Técnico em Agricultura, a disciplina Extensão Rural, no primeiro semestre do curso, integrando o módulo básico, seguido pelo módulo de Culturas Anuais e Temporárias e, por fim, pelo módulo de Culturas Perenes e Manejo Sustentável. No último, havia ainda as disciplinas de Sociologia Rural e Agroecologia, entre outras.

$\mathrm{Na}$ disciplina Extensão Rural são abordados, segundo a ementa, temas como processos de difusão de inovações, desenvolvimento de comunidades e a PNATER. Difusão de inovações, como tratamos anteriormente, é um processo que visa a persuadir o agricultor a adotar os pacotes tecnológicos ofertados pelos extensionistas. Já com relação ao desenvolvimento de comunidades, Ammann (1992) afirma que se trata de programas de desenvolvimento que apresentam uma visão acrítica e classista da sociedade, que procuram não modificar estruturas que geram desigualdades sociais.

Quanto à bibliografia, encontramos pouca relação com o quefazer atual do extensionista. De maneira geral, apresentava poucas obras específicas sobre Extensão Rural, além de não serem recentes, a exemplo de $A$ extensão rural no Brasil: da anunciação ao milagre da modernização agrícola, de Oriowaldo Queda e O extensionista do mexicano Felipe Santander. Para Bergamasco (1988, p. 196). Essa última é uma obra teatral, que retrata a história de um engenheiro agrônomo que, ao iniciar suas atividades profissionais com o campo da Extensão Rural, convive com pequenos produtores ameaçados de perderem suas terras pela ação de grileiros. "O técnico enfrenta um emaranhado de conflitos e tensões, e o seu posicionamento é que garantirá, ou não, a construção de uma nova ordem social".

Quanto à modernização agrícola referida na obra de Queda, é sabidamente um dos desdobramentos da inclusão da Revolução Verde em nossas agendas, que, apesar de ter provocado mudanças no aumento da produtividade, pouco teve importância no questionamento dos problemas sociais do meio rural. Esse processo de modernização, grosso modo, significa a subordinação da agricultura ao 
capitalismo, através do uso de sementes modificadas, maquinário pesado e insumos, seguindo as regras internacionais da produção de commodities agrícolas.

Apesar de constar referência à PNATER, não encontramos discussão relacionada a essa política, ou bibliografia que abordasse o tema. Em todo caso, não tivemos acesso ao Projeto Político Pedagógico do curso, pois, segundo a Coordenação de Ensino da instituição, o documento estava em processo de restruturação e encontrava-se prestes a ser enviado ao conselho superior do órgão.

Analisando o ementário de outras disciplinas, tais como Agroecologia, ministrada no terceiro módulo do curso, também não percebemos discussões sobre a Extensão Rural como apoio à agricultura familiar.

De maneira geral, nos dois cursos analisados, também não observamos uma infraestrutura adequada para realização de atividades práticas que visassem a colocar os estudantes em contato com a realidade de homens e mulheres do campo, permitindo levá-los a uma reflexão sobre o extensionismo desenvolvido por diversos órgãos em pequenas propriedades rurais e/ou assentamentos.

Acreditamos que entender o trabalho como princípio educativo está ligado a compreender a relação indissociável entre trabalho, ciência e tecnologia. Porém, essa relação não é sinônimo de aprender fazendo, mas considerar que o ser humano é produtor de sua realidade e, por isso, pode apropriar-se dela e transformá-la. "Equivale a dizer, ainda, que somos sujeitos de nossa história e de nossa realidade. Em síntese, o trabalho é a primeira mediação entre o homem e a realidade material e social" (PACHECO, 2012, p. 67). Nesse caso, a falta de integração entre teoria e prática trabalha contra a efetivação desse princípio na formação de extensionistas rurais.

Por outro lado, em entrevista com os estudantes do IFPE sobre as concepções de extensão rural, percebemos que o discurso, de maneira geral, tendia para a ideia de levar conhecimento técnico a campo, contribuindo para o desenvolvimento agrícola, o que representa uma das marcas do difusionismo de inovações. Contudo, os discentes relataram a ideia de considerar o conhecimento prévio dos agricultores nas ações dos extensionistas, o que demonstra algum conhecimento da crítica estabelecida à extensão rural partir de Paulo Freire.

O que podemos abstrair dessas entrevistas é que - apesar da existência da disciplina de Extensão Rural, que trata sobre o assunto diretamente; bem como da disciplina Agroecologia, que abrange temas relacionados à agricultura familiar - 0 contato dos discentes com esses temas se dá majoritariamente no campo teórico, ficando a prática restrita a uma visita ou atividade didática de campo esporádica, o que é insuficiente para quem pretende desempenhar a função de extensionista rural.

Mesmo temas já extensamente discutidos, como a crítica de Freire (1983) ao sentido da Extensão Rural e temas recentes que fazem parte do cotidiano e da realidade rural brasileira, como gênero, geração, etnia, novas ruralidades, multifuncionalidade, entre outros, continuam sendo ignorados em programas de ensino, a despeito de fazerem parte permanentemente das agendas dos eventos de discussão da Ater e da agricultura fora dos moldes do agronegócio no país (SANTOS, 2014).

Por fim, julgamos que o descompasso encontrado por Callou et al. (2008), em relação a falta de integração entre os temas discutidos em cursos de pósgraduação relacionados à extensão rural e os cursos de graduação que formam mão de obra apta a lidar com esse campo, refletem também a situação da formação dos profissionais de nível técnico em Pernambuco. 


\section{CONSIDERAÇÕES FINAIS}

Observamos que o tema da formação de profissionais para a Extensão Rural está associado a uma questão política mais ampla. Acreditamos que, para esse projeto formativo, devem ser contemplados os aspectos diversos da complexidade do tema. Cabe também a necessidade de compreensão política sobre a realidade brasileira e a tomada de consciência do papel social da tarefa. As instituições de ensino que formam os profissionais atuantes nesse no campo devem apresentar, em seus planos de ensino e pesquisas, a clareza dessa intenção.

Os resultados encontrados em nossa pesquisa demonstram que os referenciais de análise e a prática continuam apontando para a predominância de um ensino cartesiano, ligado a temas como difusão de inovações e persuasão de agricultores com relação à adoção de pacotes tecnológicos, entre outros. Apesar de termos percorrido um longo caminho em direção às práticas mais sustentáveis na agricultura, o ensino de ciências agrárias continua apresentando um caráter tecnicista e promovendo pouca reflexão sobre os problemas atuais.

Acreditamos ser esse um dos grandes dilemas para a Ater, pois pesquisas recentes demonstram cada vez mais os efeitos sociais e ambientais deletérios da agricultura industrial. Enfatizamos que, no Brasil, o orçamento do Ministério da Agricultura é quase o dobro do orçamento do Ministério do Desenvolvimento Agrário, considerando os anos de 2009 a 2013 (SANTOS, 2014), o que nos dá uma dimensão da força política dos ruralistas na elaboração de políticas federais.

Ponderamos que novos referenciais de análise precisam ser incorporados aos currículos, projetos políticos pedagógicos e outros documentos referentes às instâncias responsáveis pela formação de profissionais que atuam na Ater, tanto na gestão quanto na execução de políticas. Consideramos que a formação institucional para a Extensão Rural deve estar no âmbito de uma política pública própria. Essa recomendação deve incluir o incentivo aos projetos públicos e formação de formadores, em institutos de educação técnica e universidades, em processos de capacitação inicial e continuada.

Tal necessidade se justifica visando a que os egressos desses cursos tenham acesso a teorias e práticas que lhes permitam intervir junto à realidade agrária do país, na busca por agriculturas mais sustentáveis e pela melhoria de vida da população que dependa total ou parcialmente da produção agropecuária para sua manutenção e reprodução. Acreditamos que os resultados da ação da Extensão Rural repercutem no desenvolvimento da agricultura familiar, que interessa a toda a sociedade, inclusive aos contextos não rurais.

\section{REFERÊNCIAS}

ABRAMOVAY, R. Agricultura familiar no Sul do Brasil: entre setor e território. In. BEGOA, J. (Org.). Territorios rurales: movimentos sociales y desarrollo territorial em América Latina. Santiago; Editora Catalonia, 2007.

ALEMANY, C.; SEVILLA GUZMÁN, E. ¿Vuelve la extensión rural?: Reflexiones y propuestas agroecológicas vinculadas al retorno y fortalecimiento de la extensión rural en Latinoamérica. In: Foro La extensión rural en el Cono Sur, Uruguai, 2009. Anais... Acessado em: 24/04/2013.Disponível em: http://goo.gl/Ohu3vC.

ANDRADE, B. de O.; TAUK SANTOS, M. S. Extensão Rural e Cibercultura: o Facebook como ferramenta de promoção da Política Nacional de Assistência Técnica e Extensão Rural. Extensão Rural, v. 22, n. 3, 2015. 
BRASIL. Decreto no 4.739 de 13 de junho de 2003. Transfere a competência que menciona, referida na Lei no 10.683, de 28 de maio de 2003 , que dispõe sobre a organização da Presidência da República e dos Ministérios, e dá outras providências. Diário Oficial da República Federativa do Brasil, Poder Executivo, Brasília, DF, 16 jun. 2003.

Política Nacional de Assistência Técnica e Extensão Rural de 2004. Ministério do Desenvolvimento Agrário, Poder Executivo, Brasília, DF, 2004.

Lei no 11, 11.788. Dispõe sobre o estágio de estudantes; altera a redação do art. 428 da Consolidação das Leis do Trabalho - CLT, aprovada pelo Decreto-Lei no 5.452, de 10 de maio de 1943, e a Lei no 9.394, de 20 de dezembro de 1996; revoga as Leis nos 6.494, de 7 de dezembro de 1977, e 8.859, de 23 de março de 1994, o parágrafo único do art. 82 da Lei no 9.394, de 20 de dezembro de 1996, e o art. 60 da Medida Provisória no 2.164-41, de 24 de agosto de 2001; e dá outras providências. Diário Oficial da República Federativa do Brasil, Poder Executivo, Brasília, DF, 26 set. $2008 d$.

Lei $n^{\circ} 12.188$ de 11 de janeiro de 2010. Institui a Política Nacional de

Assistência Técnica e Extensão Rural para a Agricultura Familiar e Reforma Agrária - PNATER e o Programa Nacional de Assistência Técnica e Extensão Rural na Agricultura Familiar e na Reforma Agrária - PRONATER, altera a Lei no 8.666, de 21 de junho de 1993, e dá outras providências. Diário Oficial da República Federal do Brasil, Poder Executivo, Brasília, DF, 12 jan. 2010.

BERGAMASCO, S. M. P. P. O extensionista. Cadernos de Ciência e Tecnologia, v. 5, n. $1 / 3,1988$.

BRUMER, A.; SPANEVELLO, R. M. Jovens agricultores da região Sul do Brasil. Porto Alegre: UFRGS; Chapecó: Fetraf-Sul/CUT, 2008.

BUENO, E. Náufragos, traficantes e degredados: as primeiras expedições ao Brasil. Rio de Janeiro: Objetiva, 2006.

BUNDE, A.; MENDONÇA, M. R. Os impactos ambientais dos agrocombustíveis sobre as famílias camponesas - Município de Ipiranga de Goiás/Brasil. In: IV Simpósio Internacional de Geografia Agrária. Niterói-RJ, 2009. Anais...

CALDART, R. S. Educação profissional na perspectiva da educação do campo. In: Fórum Mundial de Educação Profissional e Tecnológica. Debate 12. Anais... Brasília, 23 a 27 de novembro de 2009.

CALLOU, A. B. F. Extensão rural: polissemia e memória. Recife: Bagaço, 2006.

CALLOU, A. B. F.; PIRES, M. L. L. E. S.; LEITÃO, M. R. F. A.; TAUK SANTOS, M. S. O Estado da arte do ensino da extensão rural no Brasil. Extensão Rural, n.16, 2008.

CAPORAL, F. R. Lei de Ater: exclusão da Agroecologia e outras armadilhas. Agroecologia e Desenvolvimento Rural Sustentável, v. 4, n. 1, 2011. 
CODAI - Colégio Agrícola Dom Agostinho lkas. Plano de Curso Técnico em Agropecuária. São Lourenço da Mata: Codai, 2009.

CUNHA, S. Agricultura puxa alta do PIB, mas infraestrutura limita crescimento, 2013. Acessado em 02/01/2014. Disponível em: http://goo.gl/Ffwe4q.

FORUM NACIONAL DE ENSINO EM EXTENSÃO RURAL, 2012, Pesqueira. Moção dos Participantes da I Jornada de Ensino em Extensão Rural do Nordeste, 29 a 30/03/2012

FREIRE, P. Extensão ou comunicação? 8. ed. Rio de Janeiro: Paz e Terra, 1983.

FURTADO, C. Formação econômica do Brasil. 22. ed. São Paulo: Ática, 1987.

GIL, A. C. Como elaborar projetos de pesquisa. 4. ed. São Paulo: Atlas, 2002.

GUIMARÃES, J. R. D. O veneno nosso de cada dia. Ciência Hoje Portal. São Paulo, 16 set. 2011. Acessado em 11/10/2015. Disponível em http://goo.gl/2fbFx3.

HOFFMANN, J. H. O "lobby" agrícola e os primeiros sinais do governo Collor. Indicadores Econômicos, v.18, n.1,1990.

IBGE - Instituo Brasileiro de Geografia e Estatística. Censo Agropecuário. Rio de Janeiro, 2006. Acessado em 24/05/2013. Disponível em http://goo.gl/UITbgl.

LIMA. I. de S. Mídia educativa: o uso do vídeo no ensino técnico agrícola em Pernambuco. 2002. 192f. Tese (Doutorado em Ciências da Comunicação). Escola de Comunicações e Artes da Universidade de São Paulo.

LIMA, I. S.; ROUX, B. As estratégias de comunicação nas políticas públicas de assistência técnica e extensão rural para a agricultura familiar no Brasil. In: CIMADEVILLA, G. Comunicación, Tecnologia y Desarrollo. $1^{\underline{a}}$ ed. Rio Cuarto: Universidad Nacional de Rio Cuarto, 2008.

MEC. Ministério da Educação. Programa Nacional de Acesso ao Ensino Técnico e Emprego - Catálogo Nacional de Cursos Técnicos, Brasília, 2012. Acessado em 13/11/2015. Disponível em: http://goo.gl/QOlo3K

MINAYO, M. C. de S. O desafio do conhecimento: pesquisa qualitativa em saúde. $4^{a}$ ed. São Paulo: Hucitec Editora, 1996.

OLINGER, G. 50 anos de extensão rural: breve histórico do serviço de extensão rural no Estado de Santa Catarina: 1956 a 2006. Florianópolis: Epagri, 2006.

PACHECO, E. Perspectivas da educação profissional técnica de nível médio: proposta de diretrizes curriculares nacionais. Brasília: Moderna, 2012.

PEIXOTO, M. Extensão rural no Brasil: uma abordagem histórica da legislação. Senado Federal, Brasília, DF, 2008. 
PERDICARIS, A.; SOUZA, S. C. de. Práticas pedagógicas significativas e processo de inclusão. (Trabalho final de estágio em Pedagogia) - Universidade do Estado de Santa Catarina, Florianópolis, 2005.

PRADO JUNIOR, C. História econômica do Brasil. 35ª ed. São Paulo: Brasiliense, 1987.

ROGERS, E. M. Diffusion of innovations. $5^{\mathrm{a}}$ ed. Nova York: Free Press, 2003.

SANTOS. B. S. A. A Globalização e as Ciências Sociais. $3^{\underline{a}}$ ed. São Paulo: Cortez, 2005.

SANTOS, M. A. G. A Formação do técnico agrícola em extensão rural para a agricultura familiar: Pernambuco. 2014. 126p. Dissertação (Mestrado em Extensão Rural e Desenvolvimento Local) - Universidade Federal Rural de Pernambuco.

SILVA, J. F. G.; KAGEYAMA, A. G.; ROMÃO, D. A.; WAGNER NETO, J. A.; PINTO, L. C. G. Tecnologia e campesinato: $O$ caso brasileiro. Revista de Economia e Política, v.3, n.4, 1983.

TAVARES DE LIMA, J. R. Sombras y silencios em la educación del campo en Brasil. Um estúdio de caso desde un asentamiento de reforma agraria em Pernambuco. 2010. 575p. Tese (Doutorado em Recursos Naturais e Sustentabilidade - Agroecologia) - Universidade de Córdoba.

TRIVIÑOS, A. N. S. Introdução à pesquisa em ciências sociais: a pesquisa qualitativa em educação. São Paulo: Atlas, 1987.

WEISSHEIMER, M. A. Expansão do agronegócio oculta pesado custo ambiental para o país. Repórter Brasil. São Paulo, 06/01/2006. Acessado em 26/11/2013. Disponível em: http://goo.gl/o6WdQ2. 